\title{
Agricultural Land into the City: 5 Environmentally Sustainable Ecological Parks
}

\author{
Simona Basilico ${ }^{1 *}$, Patricio Eduardo Enriquez ${ }^{1}$, Massimiliano Bevacqua, Fabio Villa \\ ${ }^{1}$ Basilico Enriquez architetti associati, via Monferrato 7, 20144 Milan, Italy. \\ *Corresponding author: be.architetti@gmail.com
}

cross ${ }^{\text {ref }}$ http://dx.doi.org/10.5755/j01.sace.4.5.4698

The article illustrates an environmentally sustainable urban project developed in the city of Vigevano (Italy), example of a new form of planning which tends to restrict the territorial development that involves soil consumption and reduction of natural areas, especially in the fringes where the city faces to open areas. The goal is the sustainable design of open spaces without identity (urban voids) for their preservation and enhancement as well as awareness rising.

The urban voids are identified by unbuilt areas located within the cities, without functions, uses, and without any recognizable identity established by the society; typical effect of the phenomenon of urban sprawl.

The project has been developed with the financial support of the Cariplo Foundation and the commitment shown by the city of Vigevano.

Keywords: sustainable planning, land use, soil consumption, urban fringe/edges, renaturation of urban areas, Vigevano.

\section{Introduction}

In the cities there is the presence of diffuse and disorderly landlocked vast open spaces between the buildings, as a result of urbanization of land (building expansion). These areas are examples of disorder and mode of growth of many medium size Italian cities. It is a characteristic morphological result of construction processes that occurred in the 50s, when there was a lack of planning policy. But even in cities where urban expansion has taken place respecting the rules of urban planning, the same city are equipped with a series of spaces that remained partly unrealized, without identity and belonging to a specific design of the urban plan. These spaces can be defined as "urban voids", or spaces that do not contribute essentially to the livability of cities.

"Urban sprawl" is a term that indicates a rapid and disordered growth of a metropolitan area, also in mediumsized cities. This phenomenon, in most cases, is emerging in the peripheral areas characterized by the presence of areas of recent expansion and subjected to continuous changes.

The effects of urban sprawl are those of inclusion and reduction of green spaces and the consequent lack of planning of the open areas, considered less important than the built-up areas. This phenomenon of expansion of the built environment has led to a fragmentation of the same open areas and their non-recognition in the landscape (Kaplan and Austin 2004)
In Italy several decades of intense territorial development involved high soil consumption and a massive reduction in natural and agricultural areas, especially in urban and peri-urban areas (Gibelli and Salzano 2006).

The strong development pressures or requests for infrastructure are often not properly treated or properly contrasted in urban plans by government agencies. This happens due to the absence of viable alternative projects, or is determined by the need to finance the municipality budget with building permissions' economic revenue. In this way, however, it endangers the existence of the open spaces.

In Italy there is no specific legislation that regulates the consumption of soil in contrast to German law. In Germany since 1998 a law which imposes the reduction of land consumption from 130 to 30 ha per day.

In the absence of a specific Italian law, the European Landscape Convention, adopted by the Committee of Ministers of Culture and Environment of the Council of Europe in 2000, and the document of the Commission of the European Community entitled "Proposal for a Directive of the European Parliament and of the Council establishing a framework for the protection of soil and amending Directive 2004/35/EC (COM (2006) 232def)" are currently two valid references that recognize the role and functions of the open spaces in the landscape, along with the responsibility of States and individuals for their maintenance. 
In addition, in the planning process, thanks to the enactment of the instrument of the Environmental Assessment (Directive 2001/42/EC), the municipalities are called to recognize the environmental and landscape values of the area and assess the effects produced by different settlement scenarios, including in also the evaluation of the soil resource.

In the reality of Italian cities, it is therefore necessary that the redevelopment of open spaces, which must be based on processes shared by the local community, transposed into the urban plans through specific administrative acts to ensure the maintenance of open spaces and their primordial functions for the environment.

With these features and with the intent to support the dissemination of knowledge and best practices as a tool to guide the sustainable decisions and behaviors, the project intends to promote:

1. the preparation of feasibility studies of 5 areas owned by Vigevano Municipality, in order to activate redevelopment projects to consolidate the presence of significant open spaces in the city and returning them to their environmental, social or agricultural functions;

2. the census of open spaces under the risk of future construction or urbanization or in a state of decay, aimed at cataloging the territory with regard to the functional requirements and environmental conditions.

The goals pursued by the studies conducted on the 5 areas for the redevelopment of open spaces are:

- to reactivate the ecological and landscape values;

- to maintain and to qualify natural areas in urban and peri-urban areas;

- to increase the sustainable use;

- to restore and to maintain the landscape and local identity;

- to reduce human pressure;

- to protect and to enhance the identifying characteristics of the landscape;

- to compact the urban form.

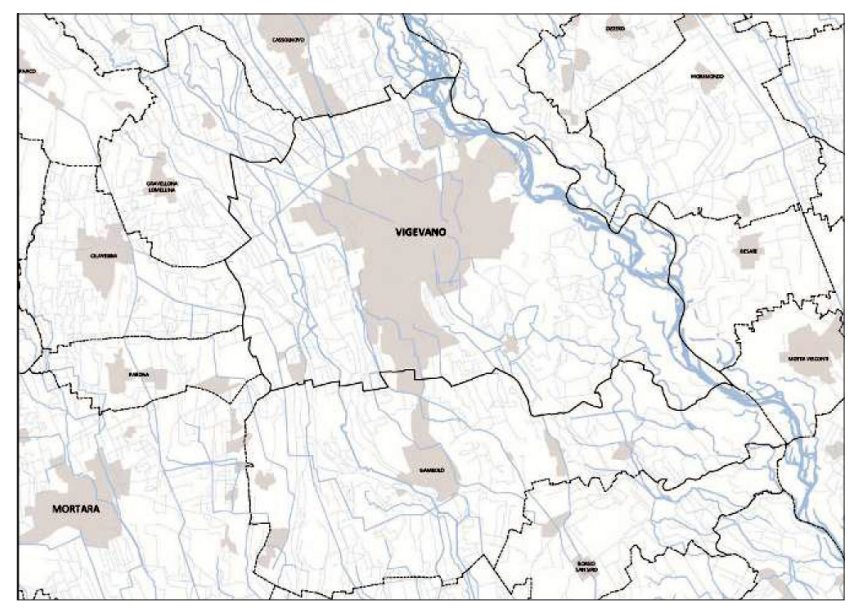

Fig. 1. Occupation of urban areas of Vigevano: the municipal area and the surrounding areas

When green areas are properly equipped in terms of environmental guarantee, they serve a plurality of functions essential to the quality of individual and social life, as well as for the environment and the landscape. They ensure the correct infiltration of water and carbon dioxide absorption, regulate the temperature and contribute to the microclimate balance and allow a large number of social functions.

To defend the open areas, their environmental functions and their management, they should be considered as important as the built-up areas, which often attract the attention of architects, planners and landscape architects.

\section{Methods}

"Agricultural land into the city" is not just a metaphor but the main goal of the project to be developed in the territory of Vigevano.

It has already been illustrated how the Italian mediumsized cities, such as the city of Vigevano, are characterized by an increasing urban density and population, a phenomenon that is likely to affect the quality of life and living. Negative effects of excessive urban expansion, especially in the areas where there are high-quality open spaces dedicated primarily to agricultural activities, are twofold: first, it destroys the quality of living and, on the other side, erases the specificity of the landscape and the natural environmental context.

The processes of urban growth have shown the presence of portions of the city, which, although constructed in accordance with the rules of development plan, were mainly built in addition to already exisiting parts of the city. In this way, the new buildings were often born with a poor relation network; not only in respect to the urban context, but also to the wider natural system of territorial and open land immediately adjacent. This also generated the widespread presence of totally anonymous areas within the building texture.

This theme is more relevant and meaningful at the edges of the city, where settlement tissue loses its coherence dispersing in the matrix of open land.

Bringing the agricultural land to the city means to trigger a reverse urbanization process. It is no longer the city to consume natural or agricultural land, but the agricultural and natural soils to reclaim parts of the city.

The 5 areas involved in the project are now "urban voids". The project works on areas without identity, without a destination and not usable by the community. Their "anonymity" makes them weak facing the urbanization process and land consumption, which by its nature expands and fills those gaps, and creates new ones.

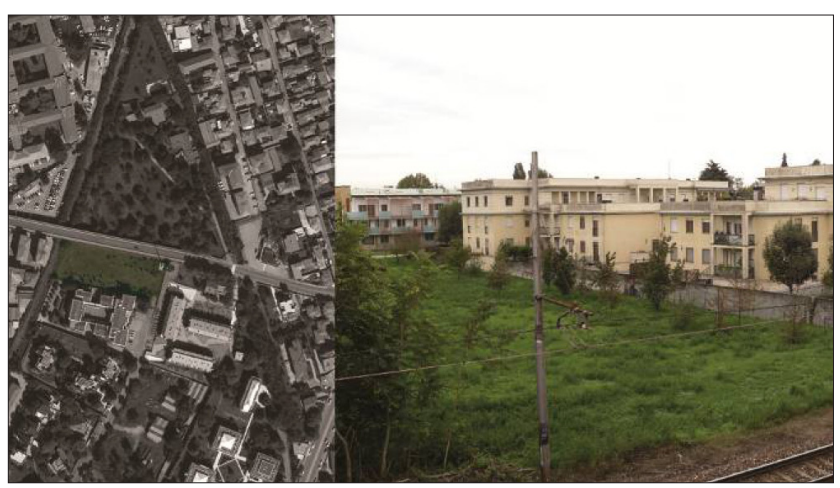

Fig. 2. Example of a typical urban void: Urban area that is not accessible, not usable and not even qualified. Via Stropeni Vigevano 
These "urban voids" derive from a mere application of the urban plan rules regarding the necessary equipment for public spaces. Spaces that have not been coordinated by a visionary project of appropriate location of these areas in the city.

The project proposes a redesign of urban form through the establishment of a new dialogue between town and country, from the natural elements (countryside) and the urban open spaces that the project renames as "ecological urban areas." This new definition expresses the importance of how areas of low value can become "heads" and the resources regenerating a new model of "urbanity".

A correct relationship between built-up areas and open areas can maintain and preserve the quality of the local environment as a reduction of environmental pressures induced by built-up areas. Therefore it is necessary to implement measures to define the urban form and the reconstruction of a suitable boundary between urban and rural areas. This need in the project has been defined as "the ruralization of the city". This is another primary goal of the project.

Numerous scientific studies have shown how the air temperature in the city is usually higher than in the surrounding countryside (Oke 1995; Bernatzky 1982). This phenomenon goes under the name of "urban heat island effect" and thus indicates the greater capacity of the built environment, than the green areas, to retain heat, so that the city is warmer due to the different metabolic activities of the city, such as heating buildings and industrial activities.

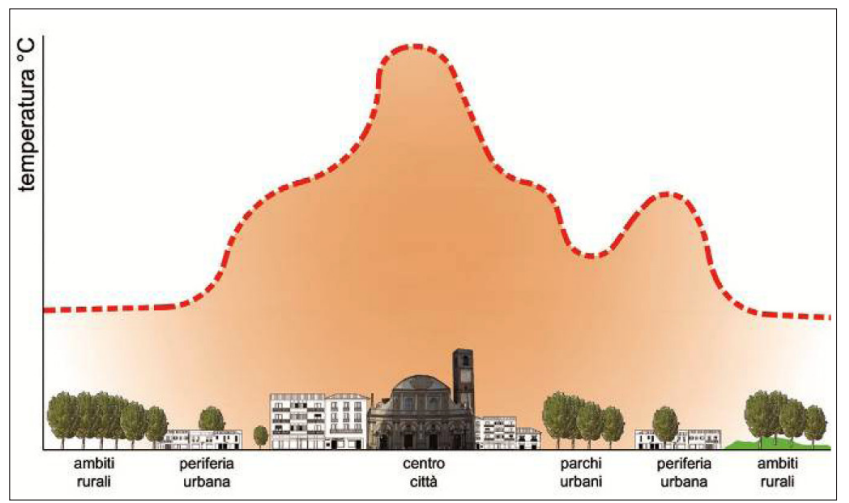

Fig. 3. Example of heat island effects: higher temperatures in the city center and consequent lowering in rural areas

The maintenance and enhancement of green areas suitably located in the city can have a mitigating effect on the micro-climate thermal properties. In this sense, the presence of vegetation contributes to the protection of people and building structures from direct solar radiation, as well as from the glare of paved surfaces. In these aspects, it adds the positive effect that the green areas may produce in residential areas for energy saving (in particular for the conditioning of air in the warm months for homes and offices).

We must also consider the problem of noise pollution that has assumed increasing importance in recent years, as a result of population growth and excessive spread of urbanized areas, as in the case of Vigevano. Even in this case, several field studies demonstrate the efficacy of the vegetation in alleviating the noise produced by traffic arteries (Wilmers 1988; Bettini 1996).

Last but not the least, it is the goal to protect and enhance the identifying characteristics of the landscape. The basic principle of this policy is the protection and enhancement of the identifying factors of places. This means remove them from abandonment to deliver them to the identity of the people.

Particular attention should be devoted to the theme of the perceived landscape, and historical landscape that does not necessarily correspond to what we see today. This refers to the theme of the changing landscape, which turns slowly or quickly, especially in the outer edge of the city where the landscape becomes sensitive element of the transformations.

One of the core functions of public spaces is to promote the meeting and integration, whether intentional or accidental. They are fundamental places for multi-purpose social communication, as well as places of recreation, psycho-physical relaxation, rest, enjoyment.

It is quite evident that the green spaces contribute also to establish an intimate bond between citizens and the urban landscape, encouraging a process of identification, which should be fostered to counterbalance the opposite process of rejection, typical of many degraded urban areas such as those examined in this project.

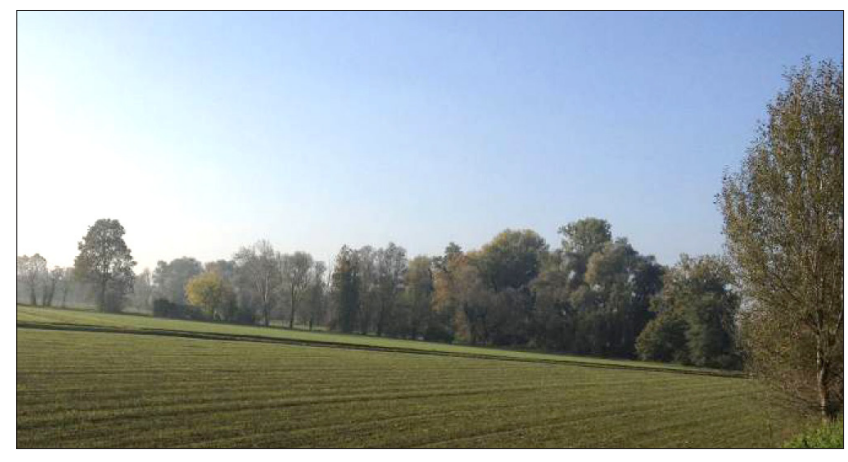

Fig. 4. View of agricultural land around Vigevano and its recognized contribution to landscape

\section{Results}

\subsection{The project context}

The city of Vigevano is located in the North-Western part of the province of Pavia, sharing a border with the Province of Milan and it is crossed by Ticino river in its eastern part.

The area, located in the irrigated plains of Lombardy, covers an area of $82.38 \mathrm{~km}^{2}$, with a population density of 732 inhabitants per $\mathrm{km}^{2}$, a much higher value than the regional average of 400 inhabitants per $\mathrm{km}^{2}$.

The irrigated plain is a part of the plain to the south of the metropolitan area of Milan. It is included in the broader interregional system of northern Italy and is mainly characterized by the presence of fertile soil and plenty of water.

These physical characteristics have resulted in a rich economy based on agriculture and breeding of animals, one of the highest productivity in Europe. The characteristic of this area is to have a strong agricultural vocation. 
Vigevano in this territory can be defined as a "city in the country", as it locates within the territorial system of the irrigated plain and in the Regional Park of Ticino, while maintaining the morphological peculiarities, economic and social structures of a large urban center.

Urban centers are surrounded by farmland and countryside is permeated by farms of high architectural value. These types of buildings, still present, represent the oldest agricultural organization of the territories.

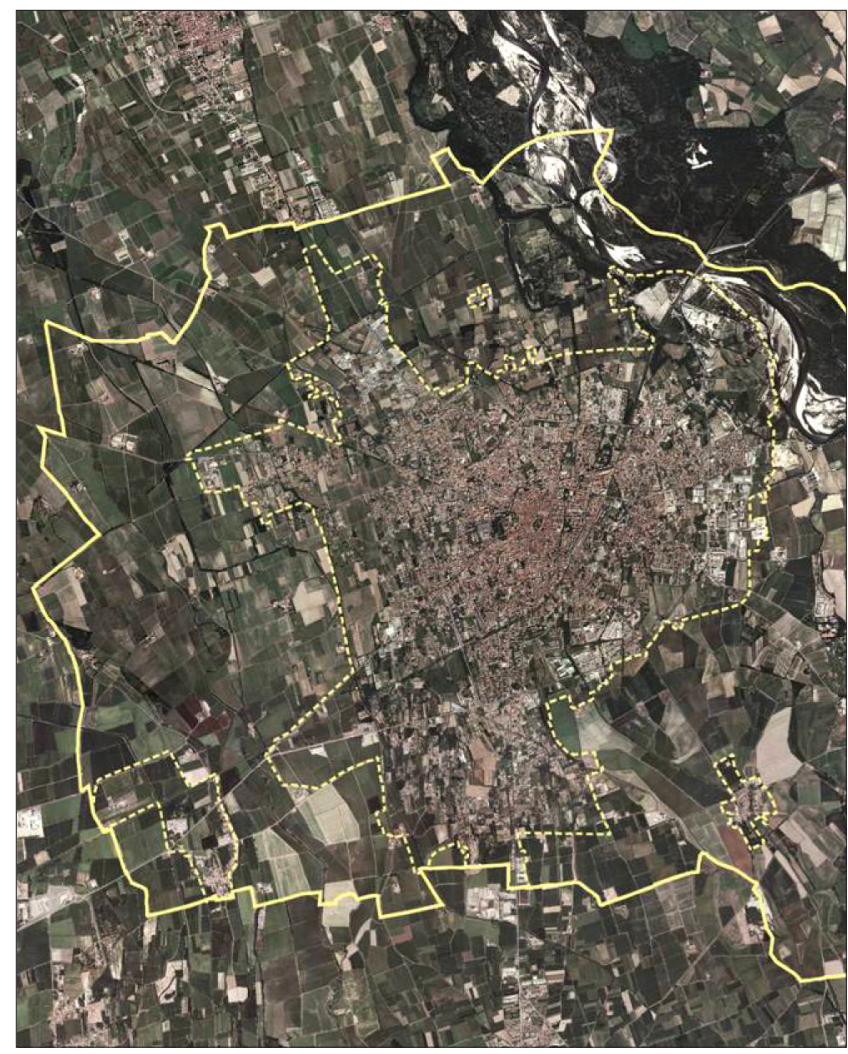

Fig. 5. The territory of the city of Vigevano. Municipal boundaries and urban areas are highlighted. Ticino river is visible on the eastern side of the map.

The city of Vigevano is the heart of an agricultural land, very compact what regards the historical city and very disaggregated what regards the expansion of the city built around the $50 \mathrm{~s}$ and $60 \mathrm{~s}$.

The sealed soil included in the urban area (AU) has an area of 2.037 ha. All the impervious urban areas reach an area of about 915 ha, $54 \%$ of the $\mathrm{AU}$, minus the area devoted to roads ( $337 \mathrm{ha}$ ). It is a rather high level compared to the level considered sufficient to ensure the capacity for regeneration of natural resources (less than 50\%).

Almost all of the surroundings of Vigevano are characterized by the presence of crops. The type of culture prevalent are paddy fields.

Agricultural areas in the territories with strong building pressure, suffer the effects of erosion, fragmentation and loss of their original role. In these areas there is a transformation of agricultural areas to service functions of urban areas.

In order to protect the presence of agricultural functions in the fringe areas, it is necessary to preserve its existence and to allow the agricultural production. This means envisage actions and tools to set up a new environmental structure of agricultural areas, also in support of ecological functions and enhancement of the landscape.

\subsection{The census}

Preliminarily, the project has conducted a census of the urban and peri-urban open areas in the territory of Vigevano. 44 open areas have been mapped and a descriptive document based on a format prepared by the Cariplo Foundation was compiled for each area. Every open area was mapped and inserted in a database loaded in the cartographic portal set up by the Cariplo Foundation.

The description sheet contains informations about the size of the area, its location, the census motivations, environmental features and urban planning.

672 ha of open areas, which are very different in structure and size, were surveyed. We based the census on principle of territorial homogeneity, so we considered as the unique bodies all the areas with similar land use and morphology. The results led to the identification of very small areas, less than 1 ha in the urban area, and areas of consistent size and low compactness in peri-urban areas.

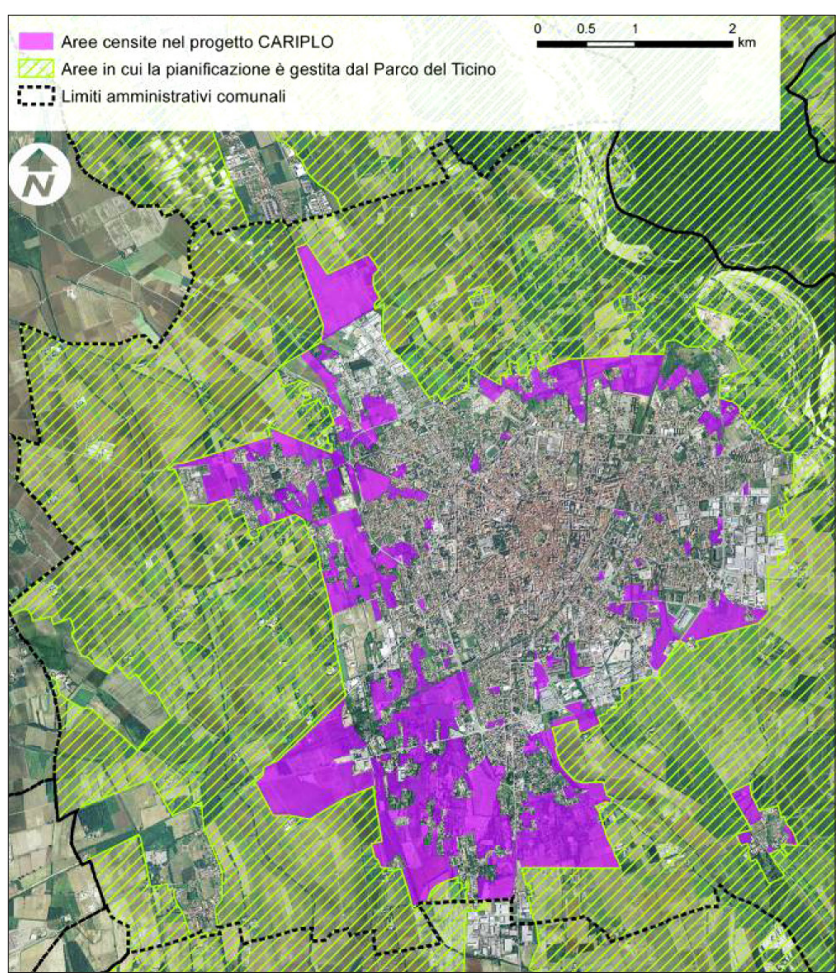

Fig. 6. Distribution of urban and peri-urban areas surveyed, highlighted in purple. The green-striped areas represent the Ticino River Regional Park

The open spaces in the urban area appear very isolated and very different from each other: they include vegetated, partially vegetated, unvegetated areas as well as areas managed and maintained with fruit trees and vegetable gardens, and areas completely abandoned and degraded.

In peri-urban areas, the principal land use is agriculture, in particular near the Ticino Regional Park the landscape tends to the typical appearance of the areas included in the park, with farms and fields, largely with paddy fields.

To complete the description of the environmentally valuable elements of Vigevano area, it is necessary to 
indicate the presence of a dense network of irrigation canals that characterize the agricultural landscape.

\subsection{The 5 environmentally sustainable ecological parks}

The project focuses on five areas of municipal property corresponding to two types of open areas: urban and periurban areas.

All areas are not managed and reach a total extension of $81.000 \mathrm{~m}^{2}$ (8.1 ha).

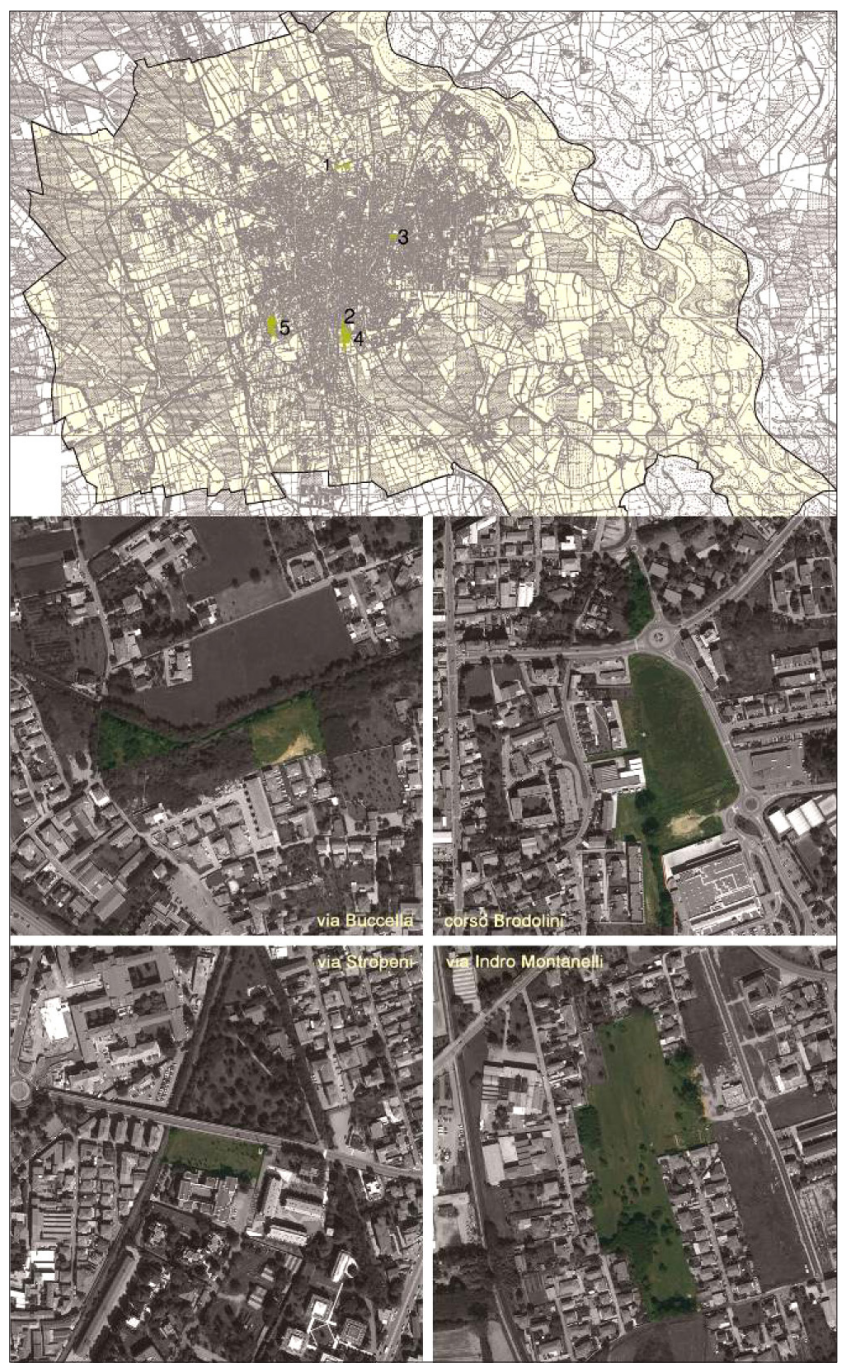

Fig. 7. Plan of the territory of Vigevano and the 5 project areas

Each area has been studied in order to:

- assess the urban situation, from an agronomic and environmental point of view;

- measure them quantitatively and qualitatively to receive an overall cognitive framework;

- identify the potential and critical issues to be solved during the design phase (feasibility studies);

- map the spatial features and relationships with the surrounding context.

\section{FREE PERI-URBAN AREA 1}

- Extension: 0.74 ha

- Type: peri-urban area

- Location: via Buccella - via Nosotti

- Prevalent land cover: degraded area, partly vegetated.
The area is adjacent to the Roggia Mora water channel. An abandoned pedestrian and cycle path runs along the southern side of the canal and represents the natural border between the urbanized area of Vigevano and the agricultural areas located to the north. The soil is composed by two distinct areas: the western triangular shaped area is characterized by the high presence of infesting plants, the eastern rectangular shaped one is instead characterized by the absence of vegetation and the presence of building rubble.

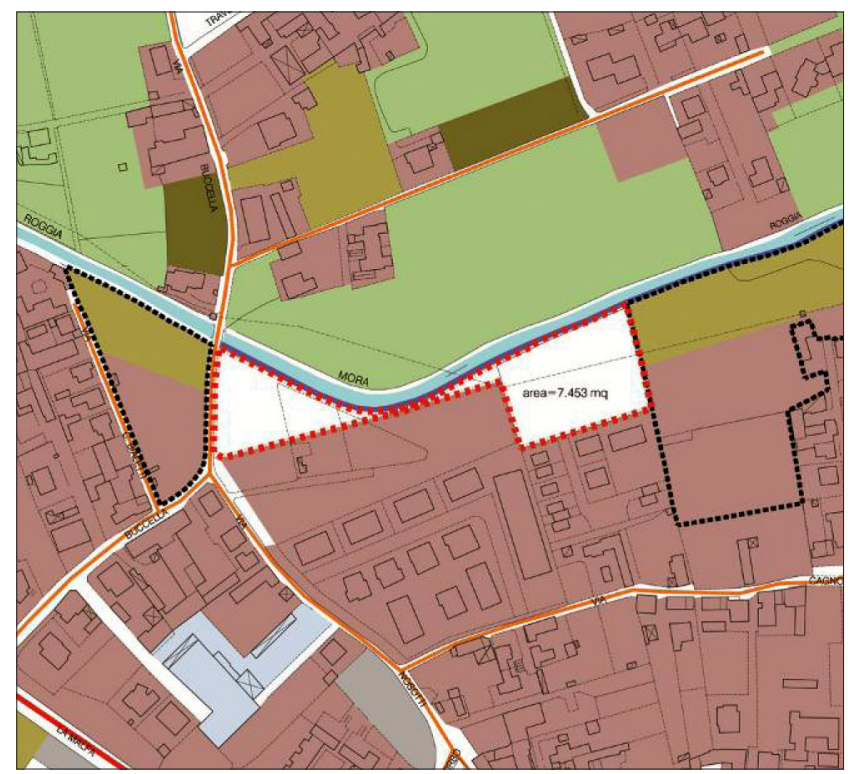

Fig. 8. Plan of urban framework. The area bounded in red identifies the project area. To the right and left, highlighted with black perimeter, extend two large open areas planned for future construction. The presence of the canal that runs from east to west; agricultural areas located to the north and the residential area existing and under development on the southern edge of the area

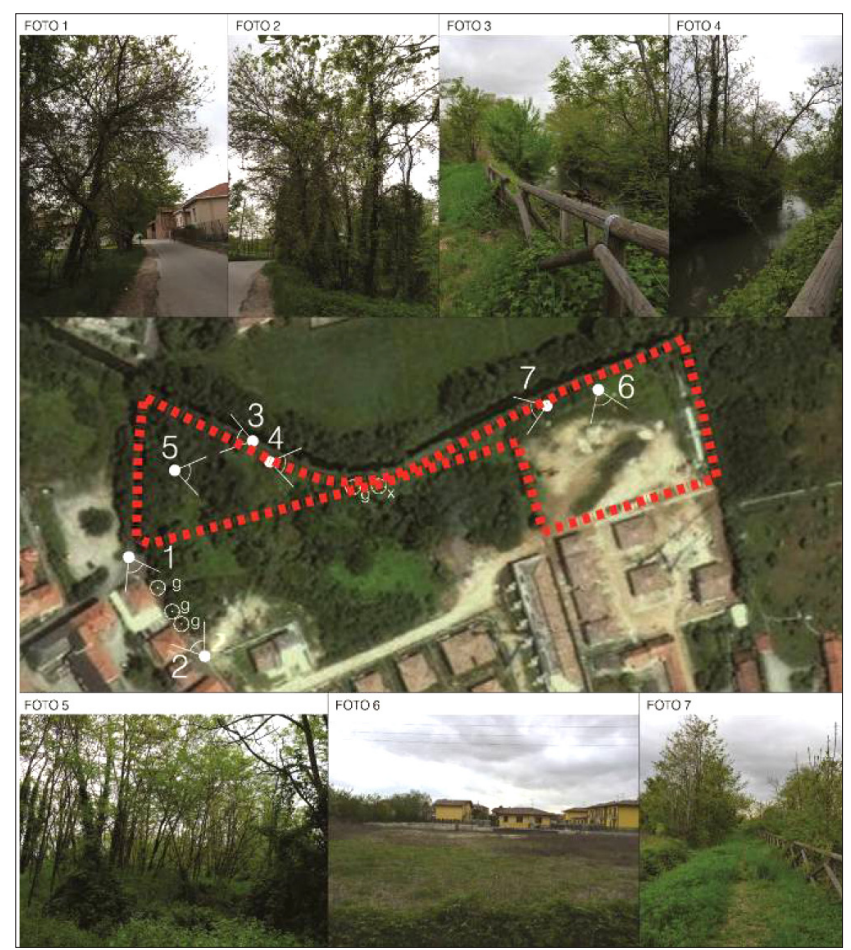

Fig. 9. Aerial photo and photographic description 
The surrounding context is characterized by the widespread presence of residential activities, particularly to the South. The area is in a strong state of decay and neglect and possesses no function except to be a critical area for further forms of degradation.

The real potentials of this area are: the presence of the canal and adjacent natural and agricultural areas, as well as the ability to be an element of organization of nature along the canal system and revitalization of this ecosystem.

The project proposal of "ruralization" of this area offers:

- the reconstitution of the existing tree patch;

- the reactivation of functional relationships and landscape in accordance with the irrigation system;

- the creation of a connection between the pedestrian and cycle path along the canal and the present urbanized area; the implementation of a wetland and the reactivation of existing sluice of the canal.

The wetland located in the center of the rectangular area also needs an environmental cleanup of the land. In the neighborhood there are natural areas (flowery meadow) and leisure areas, accompanied by a new planting of trees that will increase the existing tree density and will mask the new buildings.

The goal of the "ecological urban area" is to build a range of progression and transition from an urban area and a natural area.

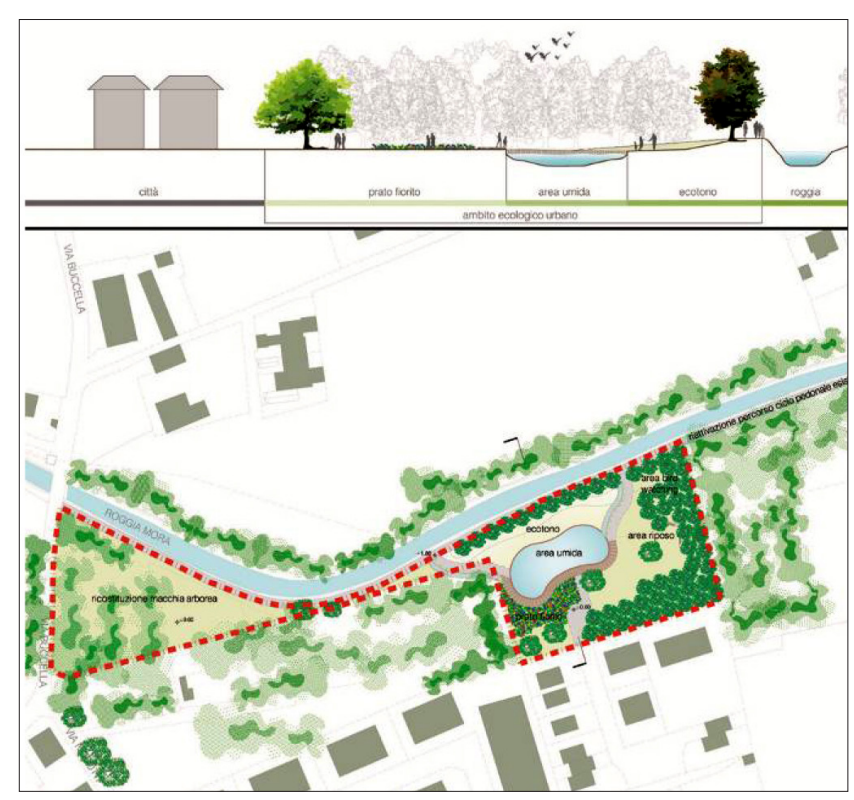

Fig. 10. Ecological Urban Area 1-Project proposal

FREE URBAN AREAS 2 and 4

- Extension: 3.90 ha

- Type: urban area

- Location: via Santa Maria - Corso Brodolini

- Prevalent land cover: forest and meadow

Both areas are characterized as urban open spaces completely surrounded by built-up areas. From the functional point of view, the built environment is characterized by a predominance of residential functions with the presence of various public facilities, such as an elementary school located in front of area 2, a kindergarten and a sports center located in front of area 4.

There are also other functions not only the residential: a new industrial site to the west of the area 4 and the large shopping center that separates hopelessly the area 4 from rural areas and the Ticino Park located in the South.

These areas are also affected by the presence of the primary road network of Vigevano (corso Brodolini).

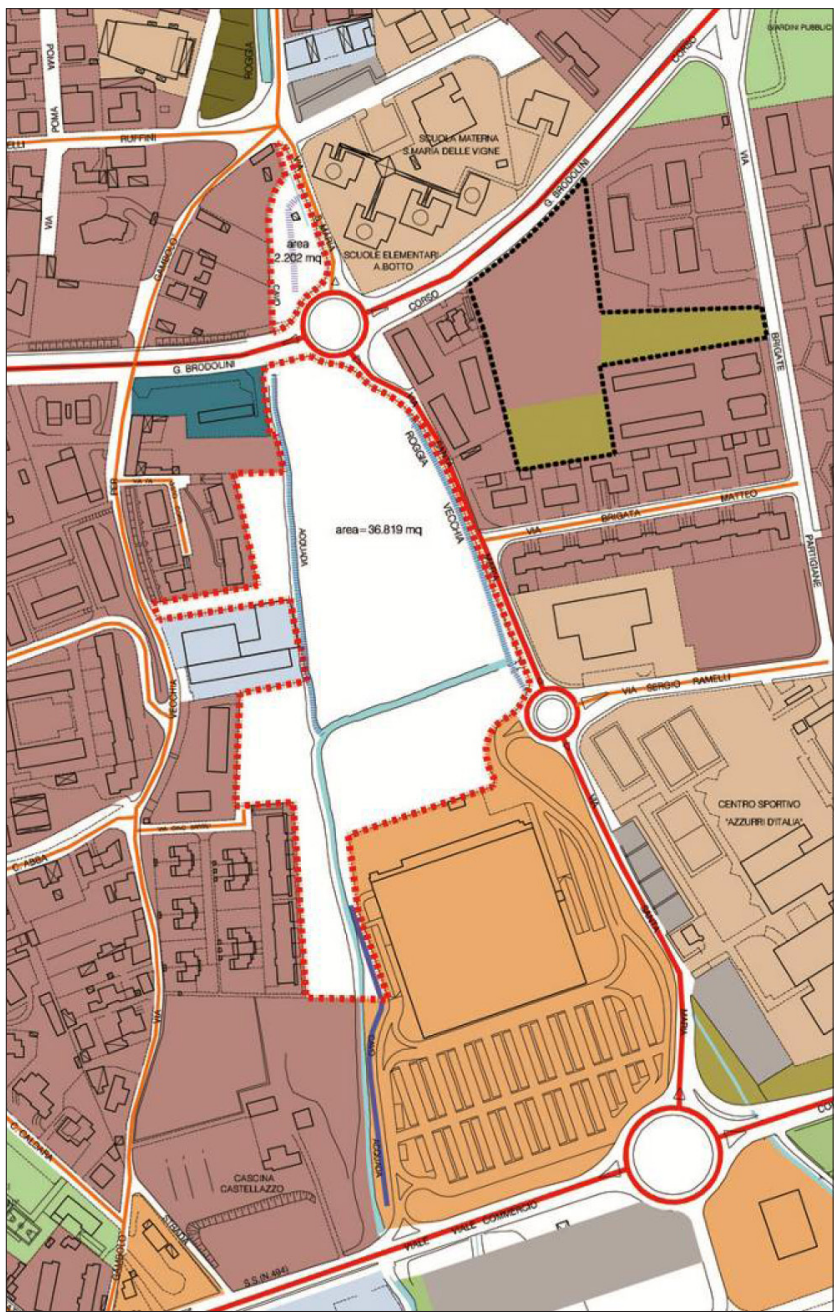

Fig. 11. Plan of urban framework. The area bounded in red identifies the project area. At the bottom there is a big shopping centre and the irrigation system. The existing road system is highlighted in red

The surrounding context is characterized by an intense building development and by a large flow of vehicles, caused by the nearby infrastructures.

These areas are not accessible from the city and do not have a high state of degradation despite the abandonment.

The qualities of these areas are: the presence of natural canals, the size compared to the surrounding built environment and their interstitial position in relation to the existing public facilities.

The project of "naturalization" proposes:

- the partial reconstruction of the existing tree scrub in area 2 ;

- the implementation of a pedestrian and cycling connection between the school buildings, the sports center, and the surrounding context. This 
circuit will connect the existing pedestrian paths directing them to the ecological urban area, thus ordering the built environment;

- the recovery of the irrigation system and its development as a structuring element of the landscape and the planting of new rows of trees;

- the creation of leisure areas that enhance the environmental characteristics. On the western side an urban vegetable garden is planned, taking advantage of the fertility of the soil and without affecting the existing trees. A flowery meadow and a leisure area will be placed in the northern areas, given the good characteristics of the soil and low environmental impact that this area receives;

- new patches of trees on the south side, in front of the shopping center. In this area it is necessary to insert a large tree planting that masks the view of the commercial structure. Furthermore, the soil requires an intervention of environmental remediation to eliminate the presence of building rubble;

- the creation of a large environmentally compatible "room" to reduce high atmospheric and acoustic impacts, through the realization of green dunes, patches of trees and pedestrian and cycle paths.

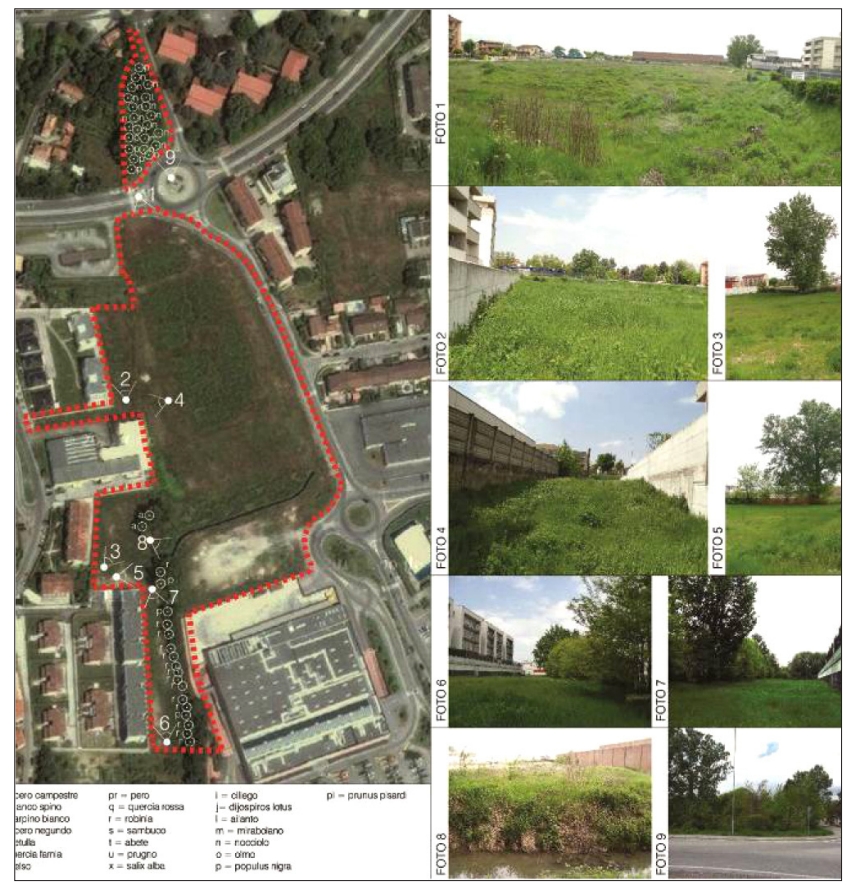

Fig. 12. Aerial photo and photographic description

This "great outdoor room", where the nature conquers space devoted to human activities, recapture a different perception of living in poorly equipped and loosely constructed areas, where the "built space" is represented by the canal, the row of trees and the green expanses.

The urban ecological area becomes an element of mitigation of environmental problems and a place of urban reconstruction.

FREE URBAN AREA 3

- Extension: 0,50 ha
- Type: urban area

- Location: via Stropeni

- Prevalent land cover: meadow vegetation

This area is particularly interesting and exemplary of building transformations that have produced this kind of "residual areas" which are not even building, being burdened by specific planning restrictions (buffer strips of road and rail) and therefore not very interesting for the real estate market.

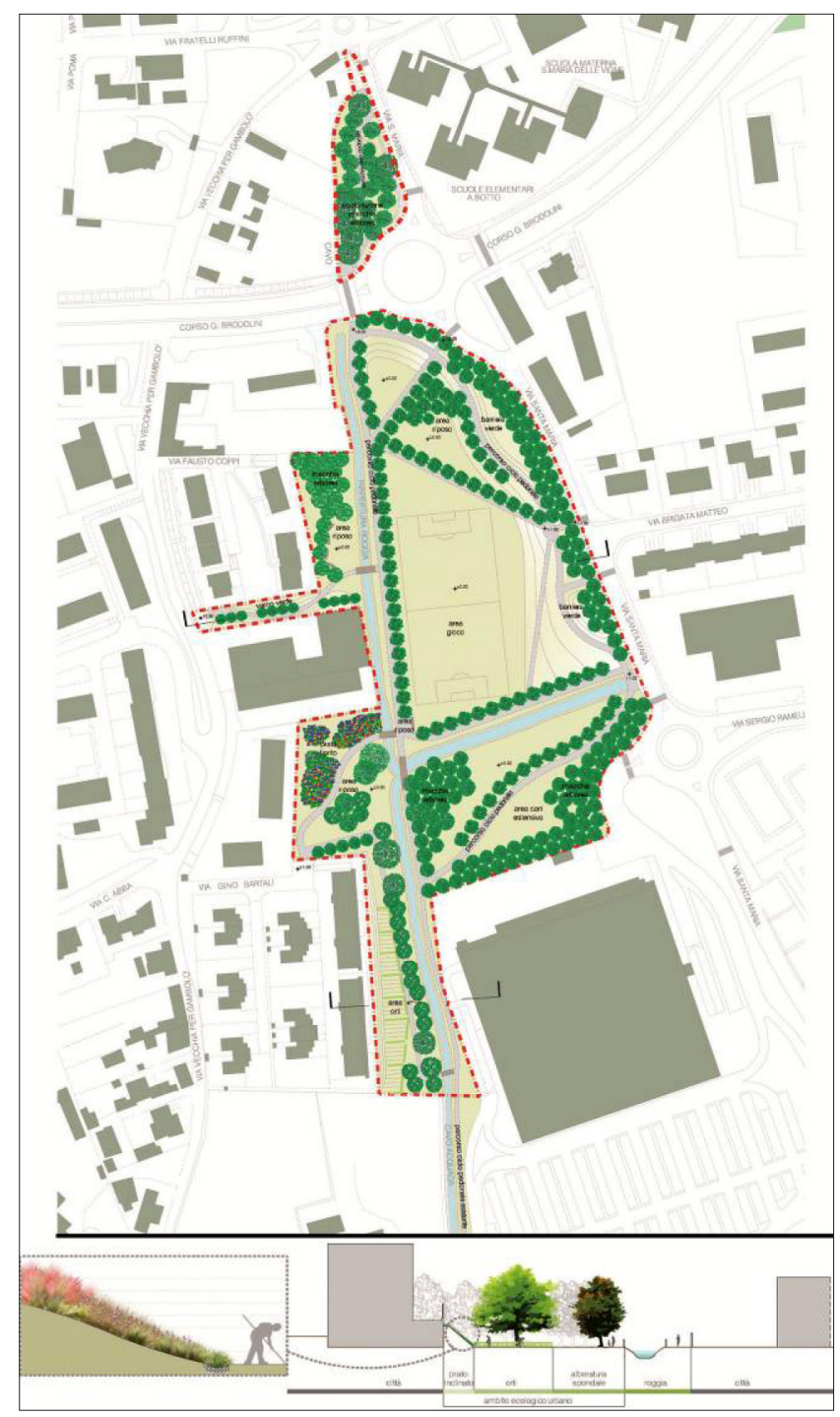

Fig. 13. Ecological Urban Areas 2 and 4 - Project proposal

The area adjoins a road viaduct and a railway line. The surrounding context, therefore, it is not immediately visible because the entire area is enclosed by road and rail infrastructure, as well as the adjacent buildings 3-4 stories high. It is wedged area and it is subject to strong environmental impacts (acoustics and atmospherics).

This space is characterized as a free urban area being completely surrounded by buildings. From the functional point of view, the built environment is characterized by a predominance of residential uses with some important public facilities, such as the Hospital on the north-west, beyond the overpass road. 
The surrounding context is characterized by an intense building development, subject to a heavy traffic of cars and trains.

This area is not accessible from the city and do not have a high state of degradation despite the abandonment.

The potential of this area are: the position between the village and public facilities, the presence of tall trees, the existence of fertile soil and the capacity to be a point of connection between different parts of the city currently separated by mobility infrastructure.

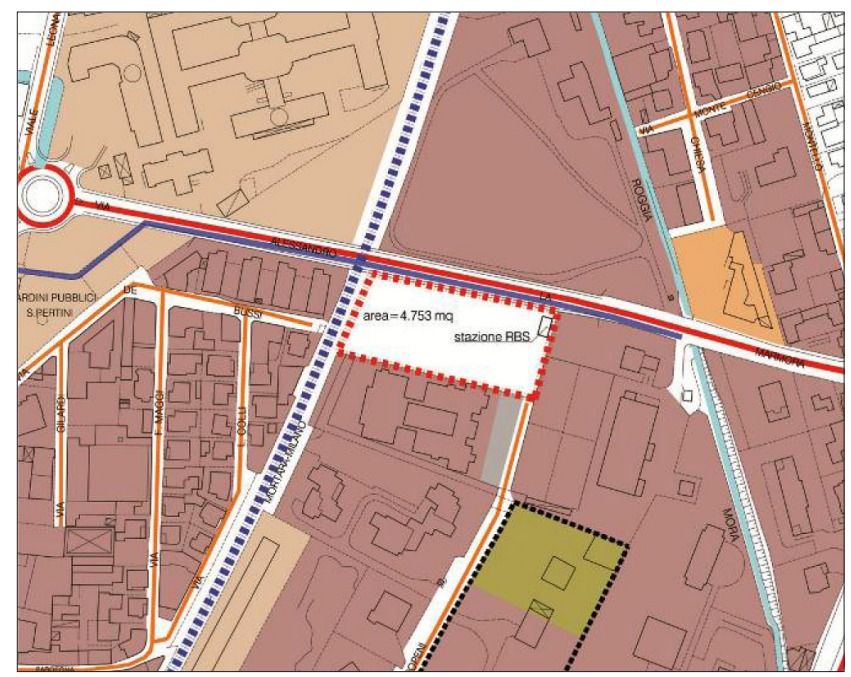

Fig. 14. Plan of urban framework. The area bounded in red identifies the project area. The overpass road is visible on the northern border and the railway line to the western one

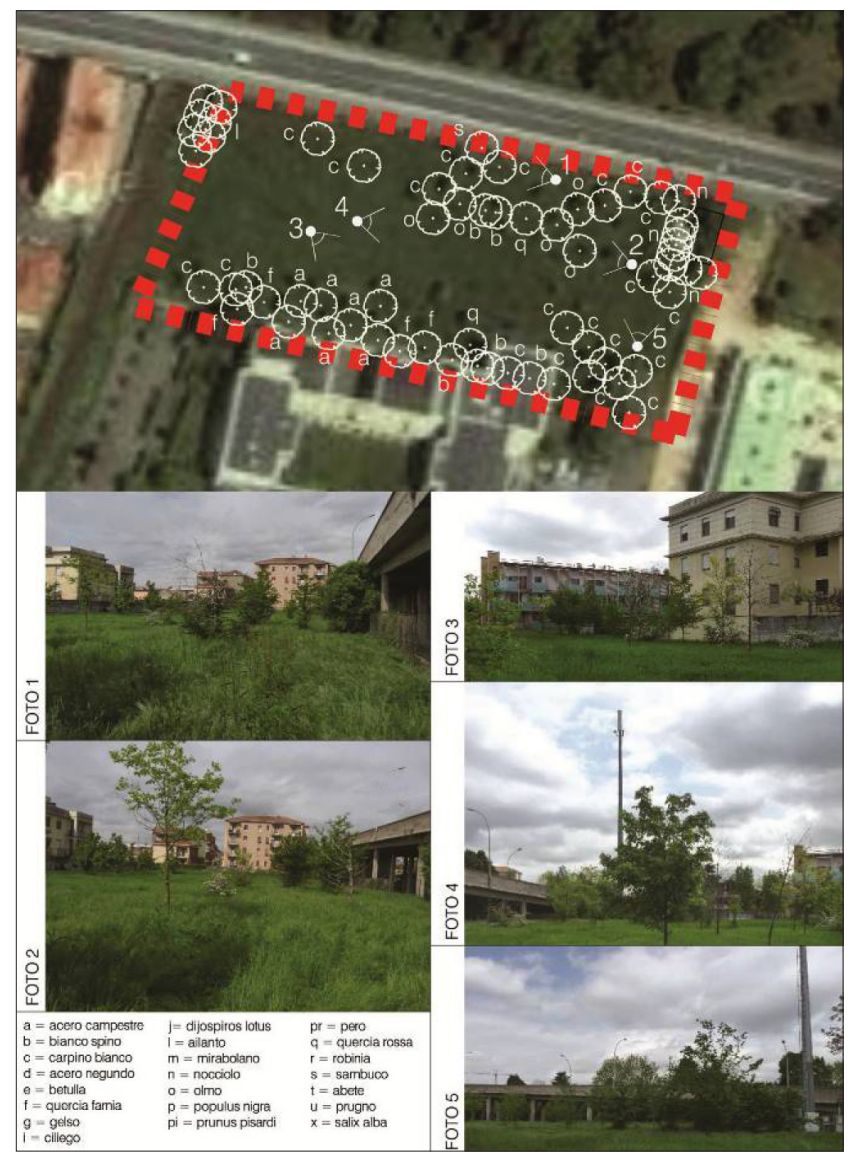

Fig. 15. Aerial photo and photographic description
The project of "naturalization" proposes:

- to make the area fully accessible through a pedestrian and cycle path. Given the strong difference in height between the ground and the overpass (about $8 \mathrm{~m}$.), the new bike path needs an extensive development to ensure a low slope, so the path is organized in a shape of " $U$ ". In this way it is also possible to build a green slope that serves to link the levels of the soil and the overpass and disguise the underlying structure of the overpass, which currently has a strong visual impact. This artificial movement of earth also creates a sort of green dune along the border west to the railroad. This combination affects only a small part of the trees present on site and helps to achieve more green barriers;

- the increase of the existing trees in order to create rows and patches of trees.

The area represents an element of urban ecological mitigation of environmental problems and natural place of transition between different urban areas.

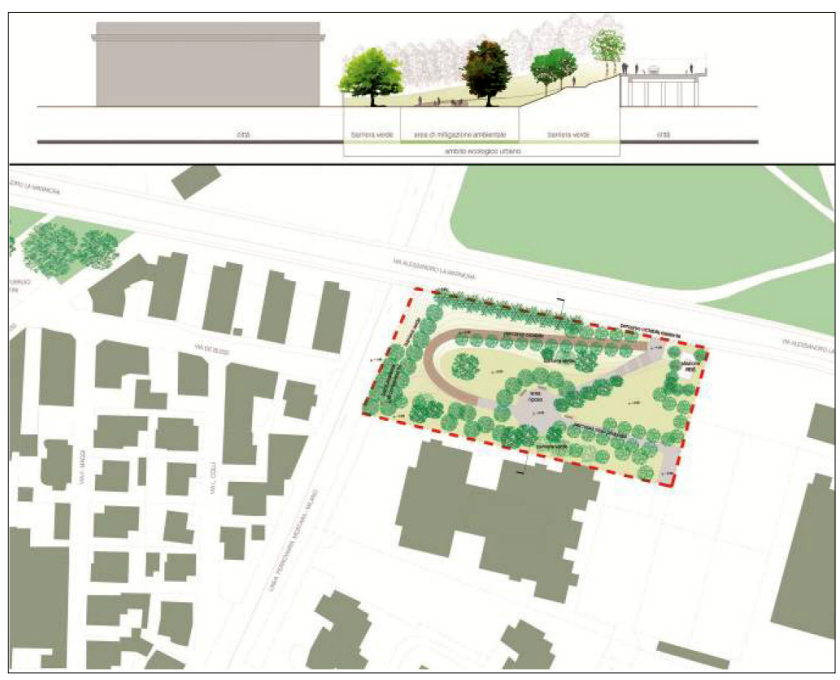

Fig. 16. Ecological Urban Area 3 - Project proposal

\section{FREE PERI-URBAN AREA 5}

- Extension: 3.1 ha

- Type: peri-urban area

- Location: via Magnanina - via Valletta Fogliano

- Prevalent land cover: meadow vegetation

The area is completely surrounded by residential buildings with low population density (one or two families), but subject to a strong future development.

In particular, the planned future construction in the south, if not framed and / or developed properly, is likely to close this open space to the immediate southern countryside.

The area from the surrounding context is hardly perceptible being enclosed by buildings, except for the southern side which appears to be the only side free of buildings in close contact with other open spaces (agricultural land).

This open space is characterized as a free periurban area. The built environment is characterized by a predominance of total residential functions, and the area is 
placed on the back of the neighbouring buildings. Existing buildings are not higher than two floors above ground.

This is a large area with a high presence of tall trees and fruit trees, and a very fertile and well-structured soil. It shows no sign of decay, despite it's not being used by people. This area has the highest level of naturalness, indeed contains significant natural and landscape values that need to be better maintained and safeguarded.

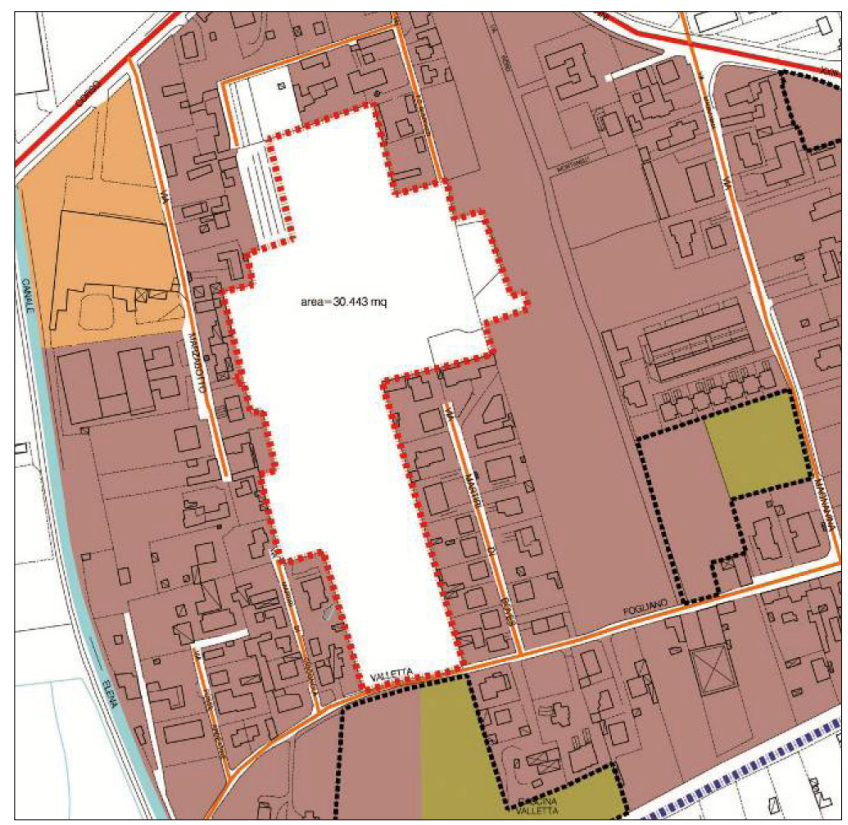

Fig. 17. Plan of urban framework. The area bounded in red identifies the project area. To the south the only free side of the area adjacent to an open area subject to future urbanization (black dotted line). To be noted the presence of other open areas subject to future urbanization, the examples of disorder and rapid transformation of the landscape

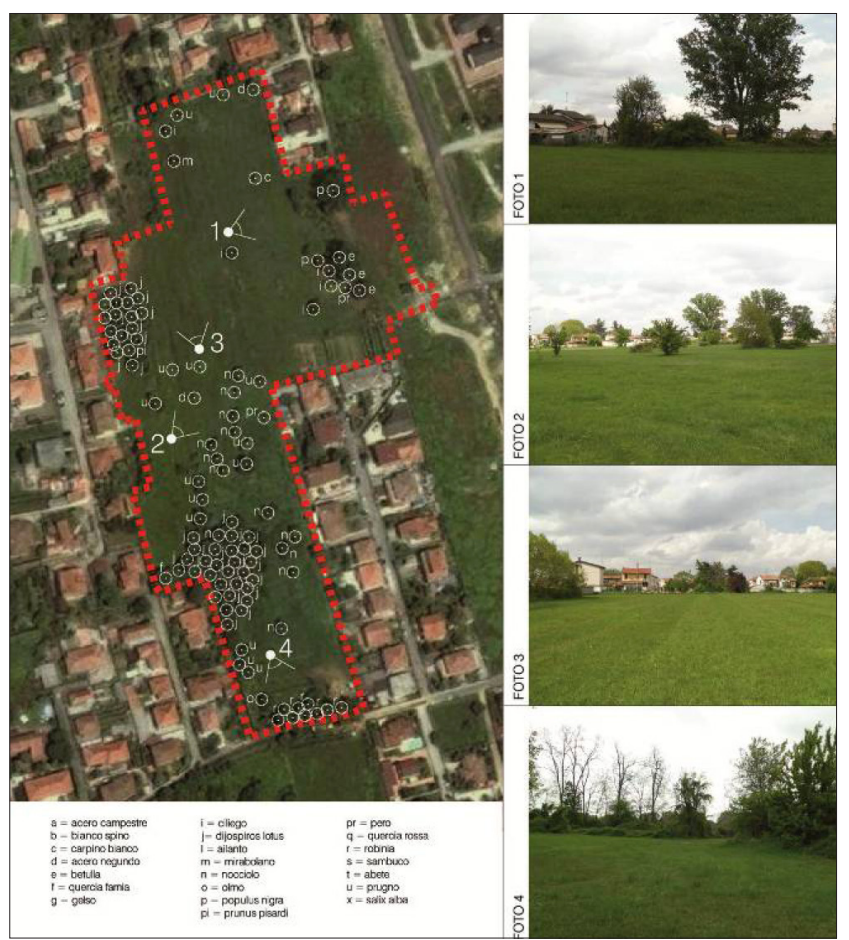

Fig. 18. Aerial photo and photographic description
The characteristics that make this area interesting are: the presence of monumental trees and a wide assortment of trees; the unity and compactness of the area; the large size and the low degree of urbanization and development pressures; the existence of structured and fertile soil.

The project of "ruralization" provides:

- the construction of a pedestrian and cycle path that connects the different parts of the buildings;

- restoring the bushes to the south of the area;

- the construction of an urban vegetable garden;

- the planting of new trees on the edges and in the center of the area. Particular attention has been paid to the arrangement of transverse rows, organizing them in order to reconstruct the evolution of adjacent properties. The goal is to create in people the spirit of "reconquest" of this space, which is now regarded as a "back" of the respective property;

- the reorganization and upgrading of spontaneous fruit trees to the north. The goal is to introduce various types of landscape into an environment with high environmental characteristics.

The ecological urban area becomes a point of transition between an urban area and a natural area.

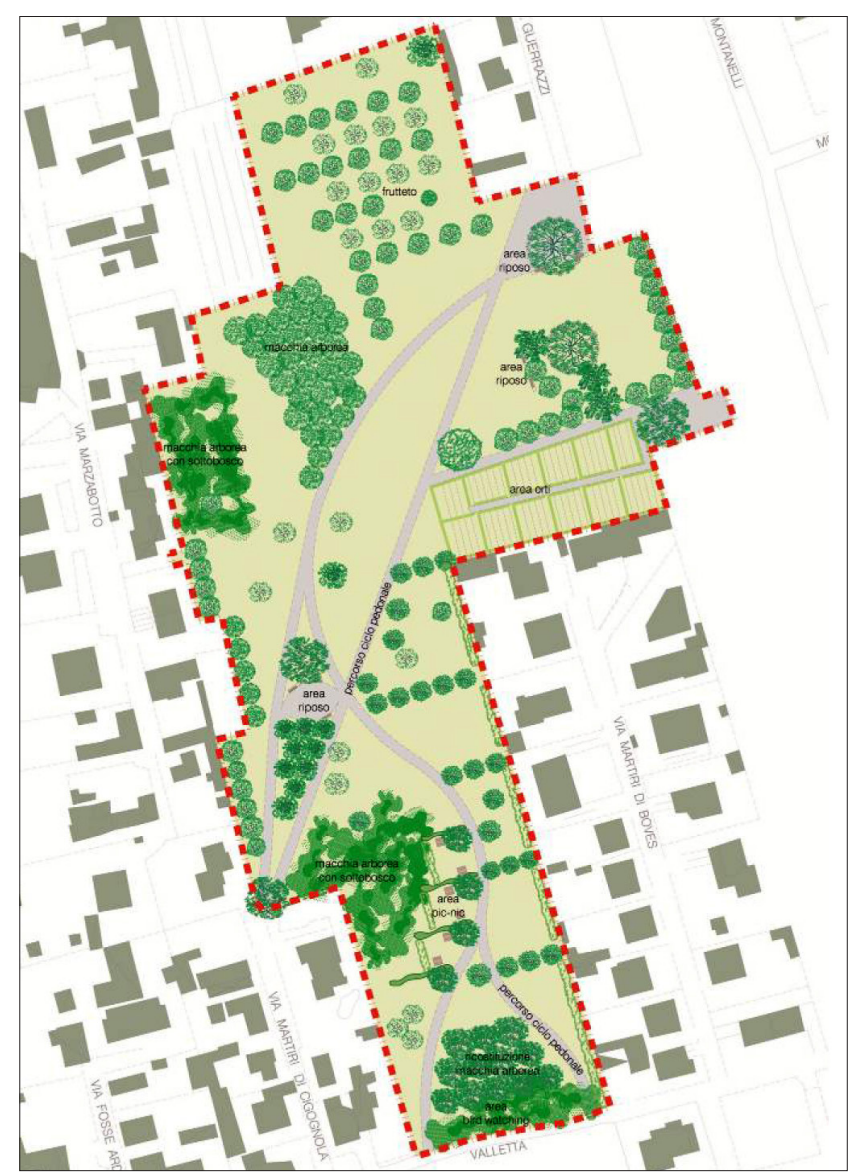

Fig. 19. Ecological Urban Area 5 - Project proposal

\section{Conclusions}

Generally the demand for urban green grows in parallel with the growth of urban congestion. The green is a public service planned and implemented by the municipalities: the quality and the amount of green per inhabitant are therefore 
a significant index of the ability of local governments to ensure sustainable development of the territory according to the needs of citizens, and the capacity to respond to progressive deterioration of the environmental quality of the cities.

The landscape is always at the center of conflict between the mechanisms of conservation and those of urban transformation that calls for new performance. The nature and the landscape can be protected only if it is implemented an environmental foresight with well-defined goals.

The 5 areas, analyzed and designed, are very illustrative of how these types of areas, which rank as "urban voids" in the cities, can bring positive changes at the environment. To preserve these areas in naturalistic terms, is necessary to introduce functions and to realize important elements capable of enhancing the ecological compatibility and the landscape of urban areas in general.

It also means to put these spaces at the service of population, build the system of "public city" and therefore contributory elements which are essential to the maintenance and strengthening of local identity of the community.

The positive effects that can be produced with the naturalistic design of the open areas are varied. From the environmental point of view, the subtraction of the areas from sealing will assists the protection of the territory from the immoderate consumption of soil. Furthermore, the presence of substantial green areas within the built-up areas can reduce the environmental impacts produced by strong anthropogenic density of urban areas in terms of lowering of the temperature and air quality, as it was already described.

From the landscape point of view, the development of interventions to experiment with "counter-urbanization and pro-ruralization" leads to the implementation of open spaces in cities and nature at the gates of the city. From the social point of view, the introduction of a new mode of space use and allocation of natural environments helps to improve the quality of living and the agricultural activities, as well as the presence of nature in the cities.

This work has also developed the theme of "modern urban park", which can be an example of how to structure a natural connection between the city and surrounding agricultural land. This activity has combined planning and design and can develop anywhere in the world, it is only necessary to protect the fundamental identities and specific characteristics of each territory.

\section{References}

Bernatzky A. 1982. The contribution of trees and green spaces to a town climate. In: Energy and buildings, Vol. 1(1), 1-10.

Bettini V., 1996. Elementi di ecologia urbana [Elements of urban ecology]. Torino, Einaudi.

Gibelli M.C., Salzano E. 2006. No sprawl. Perché è necessario controllare la dispersione urbana e il consumo di suolo [Why is it necessary to control urban sprawl and land consumption]. Firenze: Alinea.

Kaplan R., Austin, M. E. 2004. Out in the country: Sprawl and the quest for nature nearby. Landscape and Urban Planning, Vol. 69(2-3), 235-243. http://dx.doi.org/10.1016/j. landurbplan.2003.09.006

Oke, T.R. 1995. The heat island of the urban boundary layer: characteristics, causes and effects. In: Cermak J.E. Wind Climate in Cities. Dordrecht, Kluwer Academic Publishers, 81-107. http://dx.doi.org/10.1007/978-94-017-3686-2_5

Wilmers F. 1988. Green for melioration of urban climate. In: Energy and buildings, n. 11, pp. 289-299.

Received 20130627

Accepted after revision 20131010

BE ARCHITETTI ASSOCIATI - professional firm founded by architects Simona Basilico and Patricio Enriquez. Its activities include urban planning, landscape and urban environment and welfare, as well as issues on sustainable development and governance of urban planning through participatory processes. Patricio Enriquez is professor of urban planning at the School of Architecture at the Politecnico di Milano.

Address: via Monferrato 7, 20144 Milan, Italy.

Tel.: $\quad+390249434126$

E-mail: be.architetti@gmail.com

Massimiliano BEVACQUA - degree in Human Sciences Environment, Land and Landscape and Urban Planning and Territorial policies. Works on environmental and territorial policies, with particular attention to participatory planning processes.

Address: via Comasinella 14, 20801 Cesano Maderno, Italy.

Tel.: $\quad+393491942820$

E-mail: maxbevacqua@gmail.com

Fabio VILLA - degree in Environmental Science, PhD in Geological Sciences. Free-lance consultant on environmental assessments and GIS/geomatics. Works on environmental analysis and geographic data surveying and processing.

Address: via Fiuggi 40 - 20159 Milan, Italy.

Tel.: $\quad+393475409573$

E-mail: fabiovilla.studio@gmail.com 